\title{
Influence of Early and Late Fuel Injection on Air Flow Structure and Kinetic Energy in an Optical SIDI Engine
}

Hao Chen University of Michigan

Hanyang Zhuang Shanghai Jiao Tong University

David L. Reuss and Volker Sick University of Michigan

Citation: Chen, H., Zhuang, H., Reuss, D.L., and Sick, V., "Influence of Early and Late Fuel Injection on Air Flow Structure and Kinetic Energy in an Optical SIDI Engine,” SAE Technical Paper 2018-01-0205, 2018, doi:10.4271/2018-01-0205.

\section{Abstract}

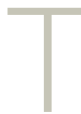

he turbulent in-cylinder air flow and the unsteady high-pressure fuel injection lead to a highly transient air fuel mixing process in spark-ignition directinjection (SIDI) engines, which is the leading cause for combustion cycle-to-cycle variation (CCV) and requires further investigation. In this study, crank-angle resolution particle image velocimetry (PIV) was employed to simultaneously measure the air flow and fuel spray structure at $1300 \mathrm{rpm}$ in an optically accessible single-cylinder SIDI engine. The measurement was conducted at the center tumble plane of the four-valve pent-roof engine, bisecting the spark plug and fuel injector. 84 consecutive cycles were recorded for three engine conditions, i.e. (1) none-fueled motored condition, (2) homogeneous-charge mode with start of injection (SOI) during intake (50 crank-angle degree (CAD) after top dead center exhaust, aTDCexh), and (3) stratified-charge mode with SOI during mid compression
(270 aTDCexh). The air flow structure (quantified by the objective metric - relevance index) and kinetic energy were examined to study the effect of the fuel spray on the air flow. The air flow was nearly identical for three conditions before the fuel injection. During fuel injection, the entrainment of air into the spray was observed near the spray but the flow structure further away from the spray was not significantly affected for both homogeneous and stratified charge modes. Right after the fuel was atomized, the spray increased the kinetic energy of air flow by $48 \pm 25 \%$ and $45 \pm 40 \%$ (average \pm standard variation, with CCV included in standard deviation) for spray at intake and compression stroke, respectively. Spray changed the flow structure and kinetic energy immediately after injection for both conditions. The changes caused by injection during intake did not affect the flow and CCV at spark timing. For injection during mid compression, both the flow-structure and kinetic-energy $\mathrm{CCV}$ were apparently affected at spark timing.

\section{Introduction}<smiles>C1C2CC12</smiles>
$s$ internal combustion engines will persist to be the main propulsion system for vehicles in the next few decades, the effort to reduce fuel consumption and pollutant emissions has to be continued. Spark-ignition direction-injection (SIDI) has been identified as a promising combustion strategy to fulfill this need [1]. Homogeneouscharge SIDI, which injects fuel at intake stroke and form a homogeneous fuel-air charge at late compression stroke, has been extensively investigated and it is in-production worldwide to replace the conventional port-fuel-injection gasoline engines.

However, the potential of stratified-charge SIDI has not yet been fully exploited. Stratified-charge SIDI injects fuel at late compression stroke shortly before ignition with engine load controlled by the fuel amount instead of restricting the engine air inlet, which eventually provides further improved fuel efficiency. The key challenge of stratified charge SIDI is to form a highly repeatable air/fuel mixture for reliable combustion in a wide range of engine load and speed.
The major reason being the short period of time between injection and ignition for the fuel to atomize, evaporate and mix with air. In addition, the turbulent in-cylinder air flow [2- $\underline{4}]$ and the unsteady high-pressure fuel injection $[\underline{5}, \underline{6}]$ result in a fuel-air mixing process with strong cycle-to-cycle variations (CCV), which eventually lead to combustion variations [7] and even partial burn and misfire [8]

Traditional diagnostics can detect the CCV but only offer global values (in-cylinder pressure, equivalence ratio, etc.), which are not sufficient to identify the origin or root cause of the CCV [9]. For further development of stratified charge SIDI engines, a deep fundamental understanding of the fuel-air mixing process is a very critical step. Large efforts are being made in both laser-based in-cylinder visualization [9] and simulation models [10] to gain insight into the air-fuel mixing process.

Air-fuel interactions were studied in either quiescent air condition or well-defined air conditions. Driscoll et al. [11] demonstrated a two-camera, two-laser particle image velocimetry (PIV) system to determine the velocities of ambient 
air and the fuel at the same time in a static test cell. Zhang et al. [12] further advanced the technique to measure two phase flow simultaneously using a one-camera one-laser setup. These simultaneous measurements assisted the efforts to model the air fuel mixing process. Ghasemi et al. [13] investigated the interactions between multi-plume spray and subsonic gas jets. They demonstrated that the gas jet accelerated the spray atomization and spray altered velocity and pressure fields of the gas flow.

As the air flow within the combustion chamber is turbulent and highly transient, the spray-air interaction has to be further investigated in real engine configuration. Stiehl et al. $[14,15]$ simultaneously captured the spray structure of an outward-opening piezo-injector and air flow with the DI engine running with triple-injection mode. The authors revealed that the CCV of the tumble vortex had a big impact on the spray shape of the second injection, while the first injection was not affected. Zeng et al. [16] found the fuel spray redistributed the angular momentum of the swirling air flow, and increased the repeatability of the air flow. In addition, they [17] identified two types of flow/spray interactions, one ensured complete combustion but the other one lead to $30 \%$ partial burn cycles. Zhang et al. [18] found the increased in-cylinder tumble flow intensified the momentum change between spray and air, and promoted the formation of homogenous mixture. Chen et al. [19] studied the spray variations resulted by the air flow variations, and later the spray variations were further investigated by measuring the spray patterns in three-dimensional (3D) manner [20]. Disch et al. [21] investigated the spray-induced vortex structures within a DISI engine at $3000 \mathrm{rpm}$ using high-speed endoscopic PIV. Aleiferis and Behringer [22] investigated the spray impact on the integral length scales of the turbulent air flow at spark timing with injection at intake stroke. They found the fuel injection in early intake stroke resulted in little difference in the general mean flow structure at ignition timing, except a $~ 10 \%$ increase in the maximum velocities. The integral length scale was similar in the tumble plane for with and without fuel injection, and was increased by the spray in the swirl plane.

However, the understanding on the mechanism of air-fuel interactions is still inadequate to design stratified-charge SIDI engines with satisfactory efficiency and emissions. In this study, we investigated the air flow and fuel interaction in a production-like single-cylinder pent-roof four-valve optical accessible engine. An eight-hole DI injector was utilized. The Mie-scattering of the fuel spray, and the air flow were simultaneously captured. Data sets without spray and with spray at intake and compression strokes were recorded, enabling quantitatively study of the air-fuel interactions.

\section{Experiment}

Figure 1a shows the experimental setup for simultaneous air flow and fuel spray structure measurements. A four-valve pent-roof single-cylinder optical accessible engine was utilized in this study. Optical access into the combustion chamber was achieved by a full quartz cylinder, and quartz windows in
FIGURE 1 (a) Experimental setup for air flow and fuel spray measurements, (b) Field-of-view for optical measurement, (c) Bottom view of engine head showing the arrangement of air flow measurement plane (laser sheet) and spray plumes.

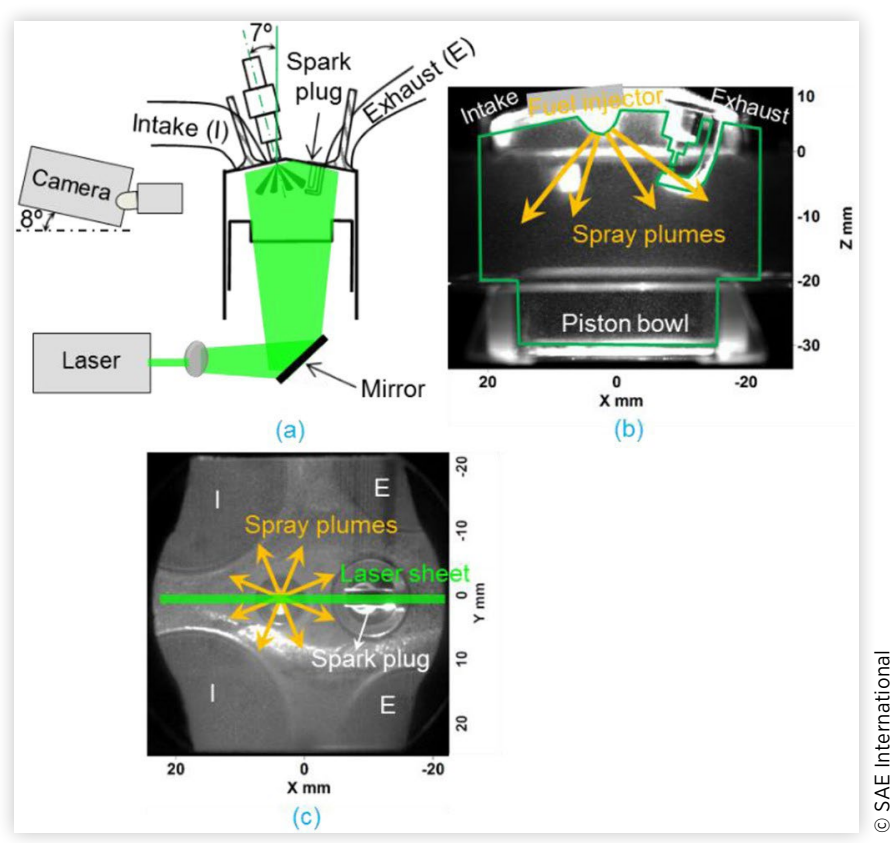

piston and engine head. Two windows at the piston side allow visualization into the piston bowl. Two windows installed in the engine head enable optical access near the spark plug and fire deck. The eight-hole fuel injector is centrally installed with an offset angle of 7 degree with the cylinder axis. The eight fuel plumes were axis-symmetrically distributed with two plumes straddling the spark plug (as shown in Figures $1 \mathrm{~b}$ and $\underline{1} \mathrm{c})$. Table 1 summarizes the engine parameters and the

TABLE 1 Engine parameters and running conditions.

\begin{tabular}{l|l|}
\hline Stroke & $86 \mathrm{~mm}$ \\
\hline Bore & $86 \mathrm{~mm}$ \\
\hline Compression Ratio & $8.7: 1$ \\
\hline Engine Speed & $1300 \mathrm{r} / \mathrm{min}$ \\
\hline Fuel & Isooctane \\
\hline Fuel Injection Pressure & $12 \mathrm{MPa}$ \\
\hline Fuel mass & $10.7 \mathrm{mg}$ \\
\hline Start of Fuel Injection (SOI) & (i)N/A, (ii)50, (iii) 270 aTDCexh \\
\hline Intake Manifold Absolute & $95 \mathrm{kPa}$ \\
\hline Pressure & \\
\hline Intake Valve Open & $-3^{\circ}$ aTDCexh @ $0.1 \mathrm{~mm}$ lift \\
\hline Motion Intake Valve Close & 220 aTDCexh @ $0.1 \mathrm{~mm}$ lift \\
\hline Filling Intake Valve Close & 231 aTDCexh @ $0.1 \mathrm{~mm}$ lift \\
\hline Exhaust Valve Open & $497^{\circ}$ BTDC @ $0.1 \mathrm{~mm}$ lift \\
\hline Exhaust Valve Close & $732^{\circ}$ BTDC @ $0.1 \mathrm{~mm}$ lift \\
\hline
\end{tabular}


experimental conditions. All tests in this study were run at $1300 \mathrm{rpm}$ with an intake manifold pressure of $95 \mathrm{kPa}$, and intake temperature of $45^{\circ} \mathrm{C}$. Two fuel injection timings were chosen, one at 50 aTDCexh for homogeneous-charge SIDI mode, and the other one at 270 aTDCexh for compressioncharge SIDI mode. None-fueled motored data was recorded for comparison. The same fuel amount $(10.7 \mathrm{mg})$ was injected for both homogeneous- and stratified- charge modes. The charge-cooling effect of the evaporating fuel reduced the peak in-cylinder pressure by $4.5 \%$ for both modes compared with the none-fueled case.

Silicone oil droplets of approximately $1 \mu \mathrm{m}$ diameter were generated by a 6 -jet atomizer (TSI model $9306 \mathrm{~A}$ ) and mixed with intake air into a turbulent flow tube ahead of the intake plenum (47 engine swept volumes) and intake runner. As depicted in Figure 1a, a dual-cavity high-repetition-rate frequency doubled Nd: YLF PIV laser (Darwin-DUO-527$80-\mathrm{M}, 527 \mathrm{~nm}, 4.8 \mathrm{~mJ} /$ pulse) was utilized. A $2-\mathrm{mm}$ thick laser sheet was created, so that the out-of-plane and in-plane spatial of the resolution (interrogation spot size) are equivalent. Dynamic laser-pulse separation was employed to achieve maximum particle-image displacements of 8 pixels. This results in a velocity dynamic range of 40:1 and minimizes in- and out-of-plane image-pair loss [23]. The maximum velocity and velocity resolution, as a function of crank angle, are shown in Figure 2. The laser sheet was reflected by a mirror under the piston, and then went through the piston window to illuminate the silicon oil droplets in the cylinder. The Mie-scattering of the oil droplets was recorded by a monochrome high-speed camera (Phantom v1610, Vision Research) with a sensor of $1280 \times 800$ pixels and 12-bit dynamic range. The camera was tilted by approximately 8 degrees (shown in Figure 1) to avoid recording the strong reflection from the engine head, and a Scheimpflug adapter was mounted between camera and lens so that a

\section{FIGURE 2 PIV velocity resolution based on 0.2 pixel} velocity resolution $[\underline{25}, \underline{26}]$ and PIV maximum velocity based on 8 pixel (a quarter of PIV interrogation window) maximum particle displacement.

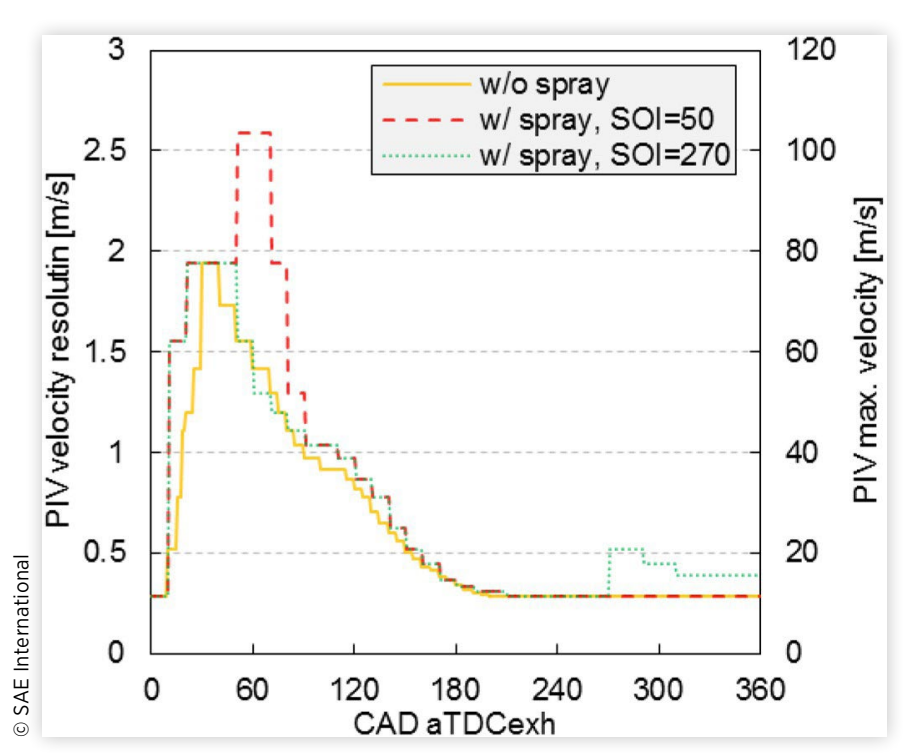

sharp focus could be achieved for the whole field of view. The Mie-scattering signal from fuel spray was much stronger than the oil droplets signal, and it was captured at the same time. The image distortion, resulting from quartz cylinder and Scheimpflug adapter, etc., was corrected by the camera calibration step. The calibration was conducted by imaging a target in cylinder and then applying camera pinhole model as fitting function. To resolve the highly transient air-fuel mixing process, the laser and camera were run at $7,800 \mathrm{~Hz}$ to achieve one velocity snapshot per crank angle, at an engine speed of $1300 \mathrm{r} / \mathrm{min}$.

Commercial PIV software (Davis 8.3, LaVision Inc.) was employed to compute the velocities. Each PIV Mie scattering image pair was cross correlated with decreasing size multipass iterations, from initial window size of $128 \times 128$ pixel to a final window size of $32 \times 32$ pixel with $50 \%$ overlap in window size. This results in a $2.5 \mathrm{~mm}$ spatial resolution and $1.24 \mathrm{~mm}$ grid spacing in the final velocity. For the CADs during the spray event, the spray region was excluded for PIV processing. To make a fair comparison, the same region was excluded for none-fueled motored condition. Peak ratios of the PIV cross correlation values were utilized to eliminate spurious or false vectors. Specifically, the vectors with the ratio of first and second highest correlation peak smaller than 1.4 were deleted. The percentage of vectors resulting from highest peak is more than $98 \%$, meaning that less than $2 \%$ of the vectors were deleted and interpolated in each velocity field. More details of the PIV setup and analysis can be found in a previous study [24].

To objectively compare the air flow, two metrics were employed. First, the relevance index $(R I)$ [27-29], which was calculated by projecting one velocity field $\left(V_{1}\right)$ on another velocity field $\left(V_{2}\right)$, was utilized to quantify the similarity of two velocity flow structures.

$$
R I=\frac{\left(V_{1}, V_{2}\right)}{\left\|V_{1}\right\| \cdot\left\|V_{2}\right\|}
$$

$R I$ varies between -1 to $1 . R I=1$ means two identical flow structure, $R I=-1$ means two exactly opposite flow structure, and $R I=0$ means two orthogonal flow structures. As demonstrated in [28], $R I$ only quantify the similarity of two flow structures and disregard the kinetic energy in flows. Second, to quantify the kinetic energy similarity, the kinetic energy ratio (KER) of two velocity fields was utilized.

$$
K E R=\frac{K E\left(V_{1}\right)}{K E\left(V_{2}\right)}
$$

\section{Results and Discussion}

This section is organized as follows. To study the air fuel interaction, the PIV data with spray during compression stroke (stratified-charge mode) was first compared with the nonefueled motored condition, and then the same comparison was made between homogeneous-charge mode and nonefueled condition. 


\section{Stratified-Charge Mode}

Before and During Fuel Injection Figure 3 shows the ensemble averaged velocity fields comparison between none-fueled condition and with spray during the compression stroke. The ensemble averaged velocity fields were obtained by averaging individual velocity fields from 84 cycles. Two CADs were compared, one at SOI timing (before fuel has appeared) and the other one at $5 \mathrm{CAD}$ aSOI, with fuel penetration about $30 \mathrm{~mm}$ along the cylinder axis. At $\mathrm{CAD}=270$, the flow structure with and without injection appeared to be nearly the same, also quantified by $R I=0.99$ for the entire field of view. The kinetic energy difference between two average velocity fields is $7 \%$, likely just due to the CCV and small sample size ( 84 cycles).

During fuel injection (CAD $=275)$, flow structures are similar in most of the regions $(R I=0.98)$. To quantitatively identify the regions where the spray has an impact, $R I$ and kinetic energy were computed at each measurement grid point. As highlighted by three ellipses in Figure 4, the spray affected the air flow with the mechanism of air entrainment $[\underline{30}, \underline{31}]$, which is a turbulent air fuel mixing and momentum exchange process. In all three ellipses, air entrainment results in an increase of the air flow towards the directions opposite to the fuel plume moving directions. At the region highlighted by the dash-line ellipse, as the entrainment was the same direction with the original air flow, the air flow was clearly strengthened. As closer to injector, the enhancement was stronger with maximum increase of more than 3 times. Figure $5 \mathrm{~b}$ quantifies this enhancement for each engine cycle, which Figure 5a provided the same information from

FIGURE 3 Ensemble averaged velocity fields from 84 cycles (every fourth vector shown).

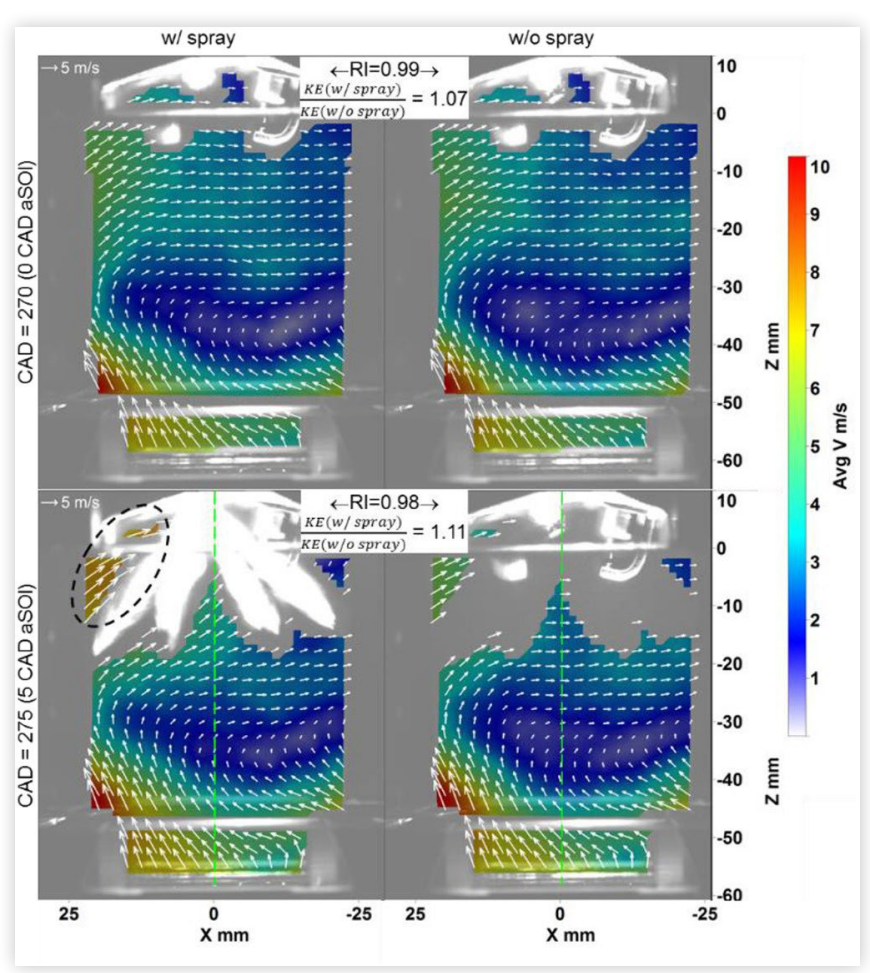

FIGURE 4 The velocity direction and kinetic energy comparison at each PIV measurement grid for CAD $=275$, between two ensemble averaged velocity fields shown in Figure 2.
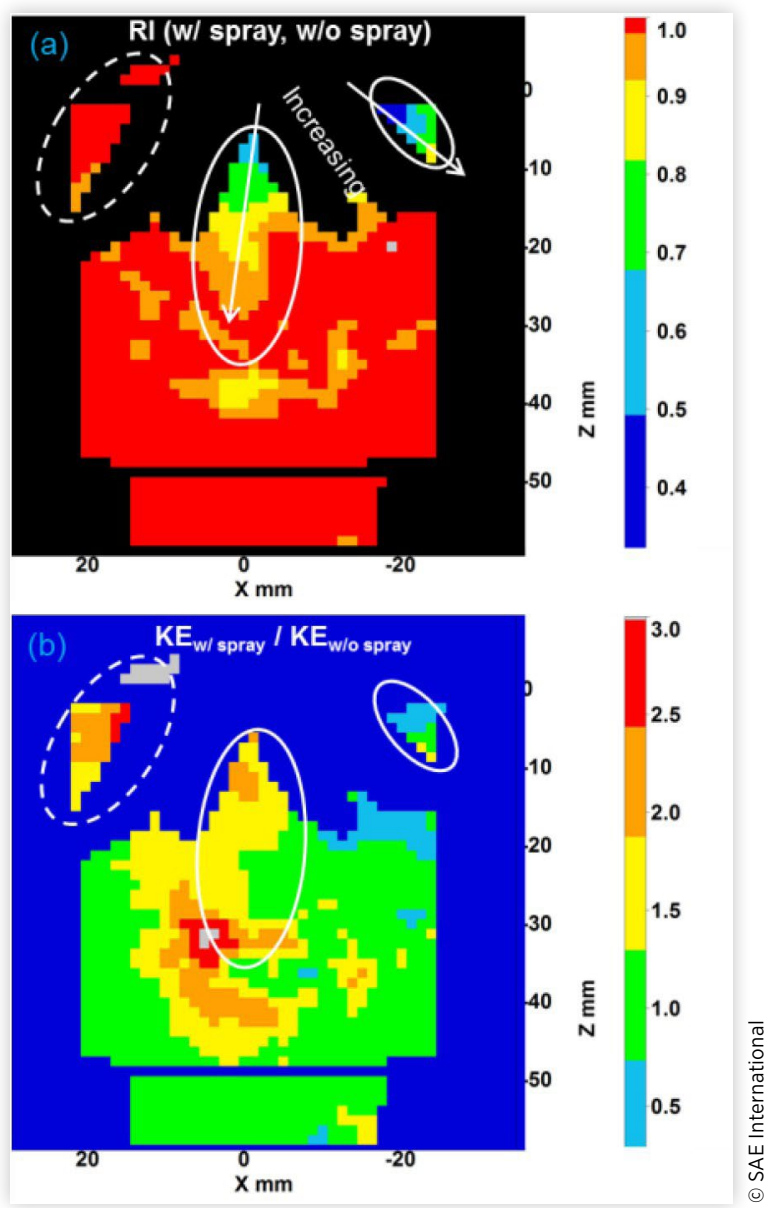

FIGURE 5 The spatial average velocity in the dash ellipse for $C A D=270$ and $C A D=275$ for each cycle.

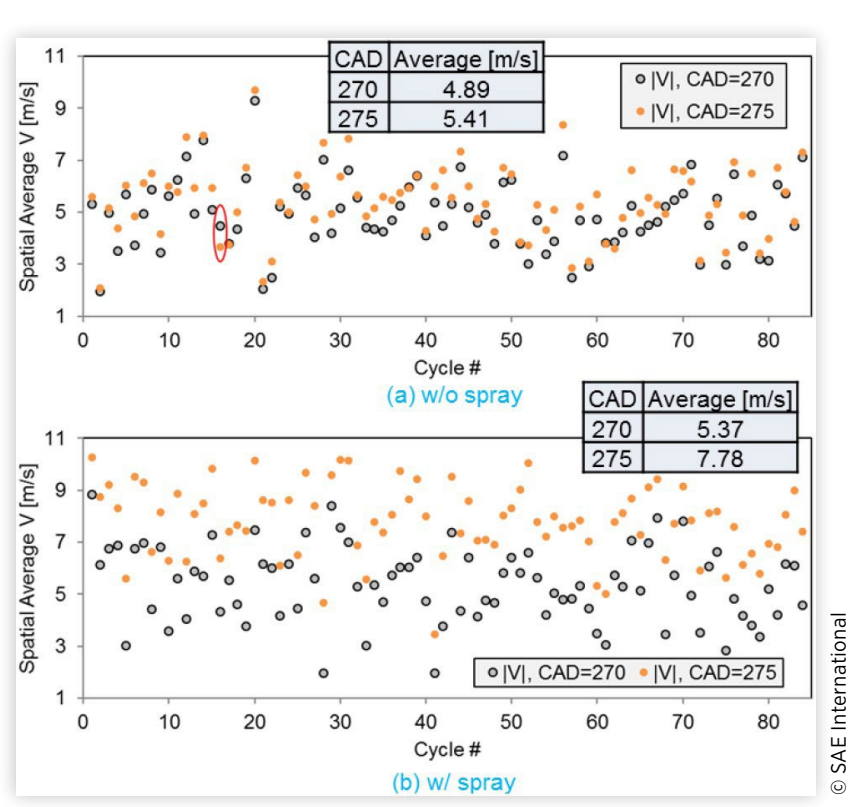

(c) 2018 SAE International. All Rights Reserved. 
none-fueled case for comparison. The average value for these four cases were included in Figure 5. As shown in Figure 5a, the velocity slightly increased for most of cycles at none-fueled operation. The flow intensity remains similar for quite a few cycles and there was one cycle (circled in Figure 5a) with air flow weakened in this region. But as quantified in Figure 5b, the spray led to an increase of air flow in this region for all 84 cycles, with an average increase of $2.4 \mathrm{~m} / \mathrm{s}$ which is nearly five times comparing to none-fueled condition.

It was obvious that the spray increased the air flow in the dash ellipse, and we did observe CCV in spray penetrations. To demonstrate the correlation between spray and air flow, Figure 6 shows the increase of air flow as a function of the spray penetration speed, which was computed along the plume centerline between $\mathrm{CAD}=274$ and 275 . The penetration speed was 70 to $100 \mathrm{~m} / \mathrm{s}$, and generally the air flow was enhanced more for cycles with faster sprays.

In the two solid-line ellipses highlighted in Figure 4, the air flow direction was changed as the original air flow direction was different with the air entrainment direction. The direction change was more significant closer to the fuel injector. In general, the air flow was enhanced along the direction opposite to the spray direction. Figure 7 quantitatively compared the two velocity components along the cylinder centerline for without and with fuel injection. The air entrainment induced by all eight fuel plumes forces the air flow upwards (positive $z$ direction). The velocity component along the cylinder axis direction increased between $z=-30 \mathrm{~mm}$ and $z=-5 \mathrm{~mm}$, the maximum increase of $3 \mathrm{~m} / \mathrm{s}$ was achieved at the point closest to the spray. As the fuel injector was offset with the cylinder axis for $7^{\circ}$ (shown in Figure 1a), the spray also slightly affected the velocity component along the $x$ direction at the spray side (Figure 7a). The CCV of both components were not significantly affected by the spray as shown by the standard deviation in Figure 7 .

As shown by the average velocity patterns in Figure 3, the large-scale flow structure was not significantly affected by the spray. To verify whether this is true for instantaneous cycles, $R I$ was computed between all pairs of cycles. Figure 8 shows the velocity fields for the two cycles with the maximum $R I$, while Figure 9 shows the least-similar two cycles. The arrows in Figures 8 and 9 demonstrate that the large-scale flow structures were very similar before and during injection for each cycle. Most- or least-similar cycles found between with and without spray cases at CAD $=275$ are not caused by the spray, because they are already most- or least-similar before injection

FIGURE 6 The increase of air flow in the dash ellipse, as a function of spray velocity (fuel plumes at the intake side).

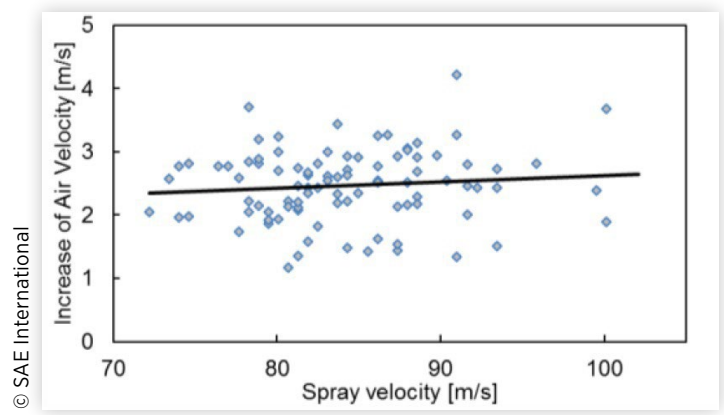

FIGURE 7 The velocity components comparison along the cylinder axis (average \pm standard deviation of 84 cycles were shown).

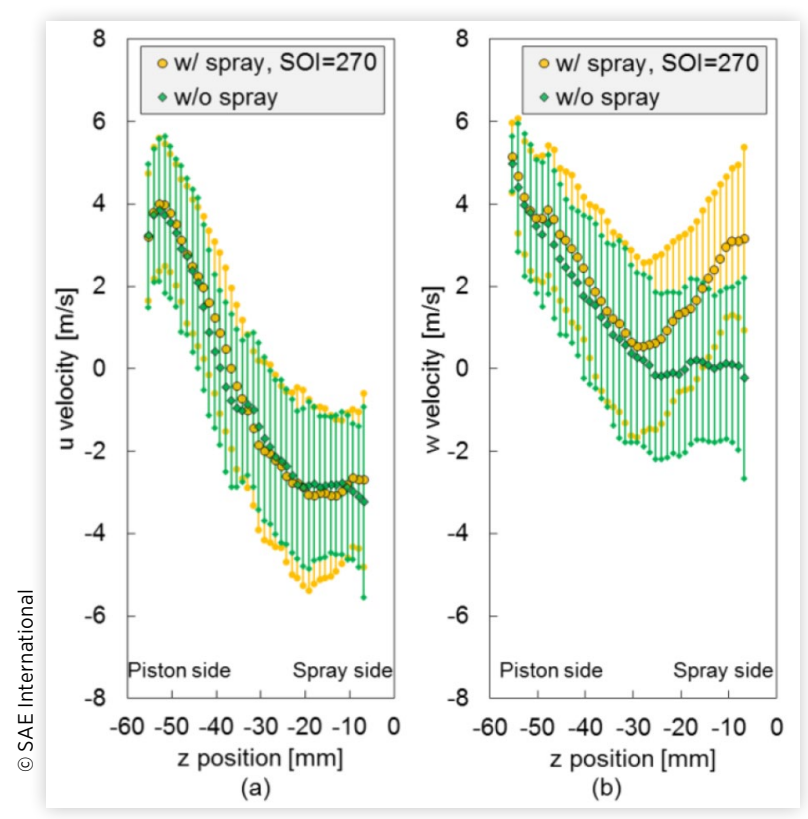

FIGURE 8 The most-similar two cycles in terms of flow structure as quantified by $R I$. The maximum $R /$ was obtained for the above two cycles.

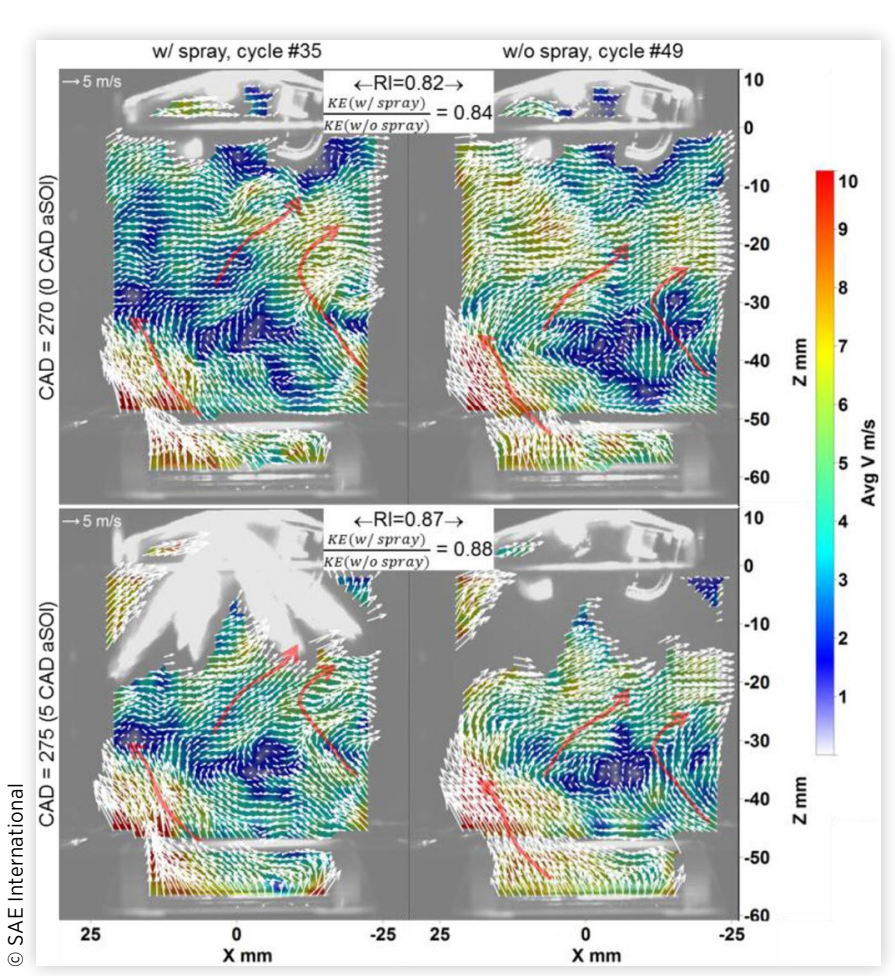

$(\mathrm{CAD}=270)$. This was illustrated for all 84 cycles in Figure 10a, in which the $R I$ between any two cycles at $\mathrm{CAD}=275$ was plotted as a function of $R I$ between same cycle-pairs at $\mathrm{CAD}=270$. As $R I$ only compares the similarity of flow structure without regard to the energy content (magnitude) [료], 
FIGURE 9 The least-similar two cycles in terms of flow structure as quantified by $R /$.

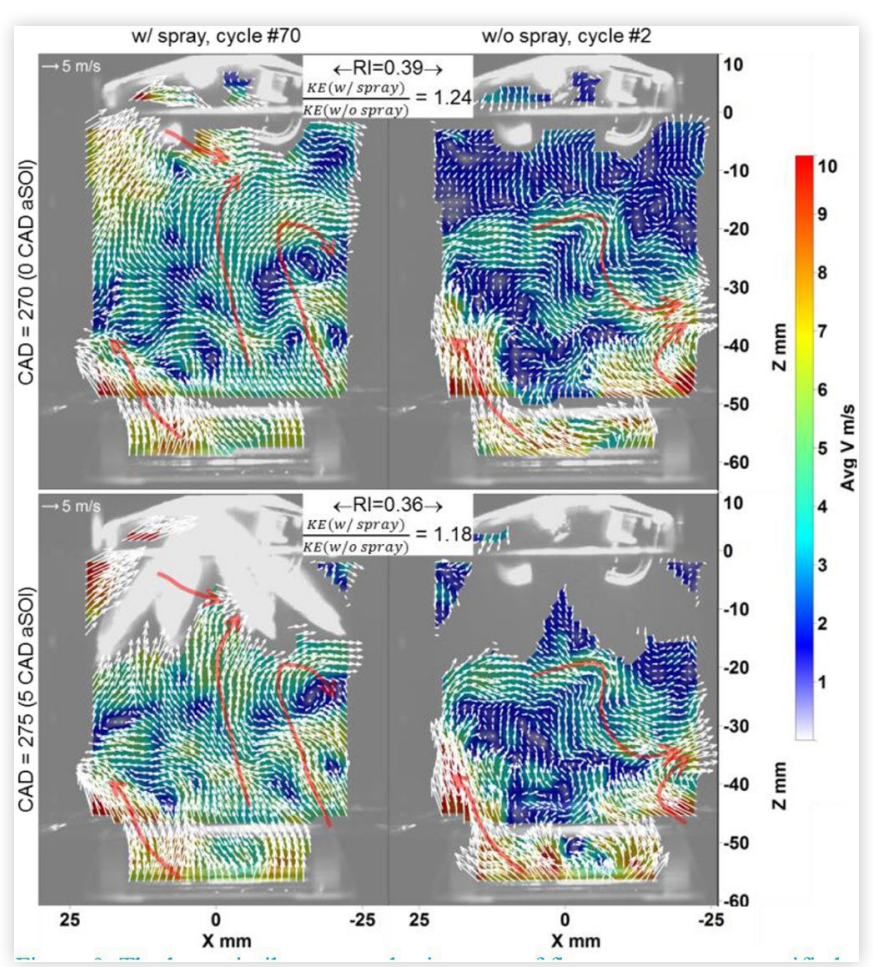

FIGURE 10 Correlation of air flow between CAD = 270 (before injection) and CAD = 275 (during injection).

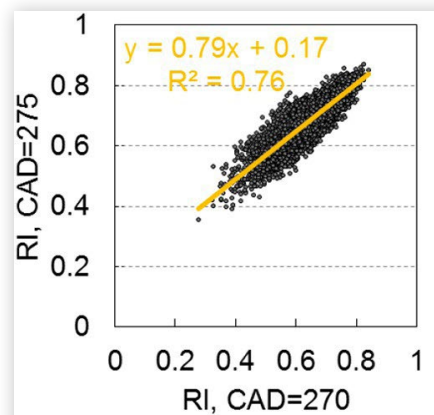

(a)

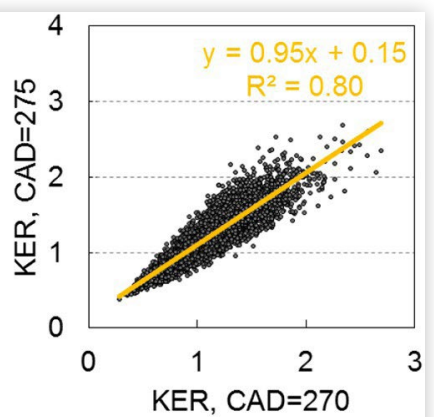

(b)
Figure $10 \mathrm{~b}$ compares the kinetic energy ratio (KER) for all pairs of cycles at $\mathrm{CAD}=270$ and $\mathrm{CAD}=275$. Good correlation is observed before and during injection, indicating that the spray was not significantly affecting the air flow.

The observations at $\mathrm{CAD}=275$ and $\mathrm{CAD}=270$ show that the flow structure and kinetic energy of the air flow in this particular measuring plane were not significantly affected by the fuel spray except the air entrainment region.

After Fuel Injection At CAD = 291 (21 CADs after SOI), the fuel was fully atomized and air flow data within the whole field of view can be obtained. Figure 11 compares the ensemble averaged velocity fields with and without spray at four CADs after injection. The $R I$ and $K E R$ between two average velocity fields were also included in the figure. The fuel injection changed the air flow structure, and increased the kinetic energy by more than $50 \%$. As highlighted by the circles in Figure 11, the air-fuel mixture impinged on the piston and rebounded off the piston $[\underline{32}, \underline{33}]$, therefore the flow in the circle was enhanced (from $\sim 5 \mathrm{~m} / \mathrm{s}$ to $\sim 10 \mathrm{~m} / \mathrm{s}$ ). However, this phenomenon was not observed at the lower-left corner. The reason was illustrated in Figure 12, in which the velocity of fuel droplets was obtained by PIV algorithm at $15 \mathrm{CAD}$ aSOI. The tumble air flow entrained the fuel droplets between the plumes, carrying them upward on the left, and enhanced the

FIGURE 11 Ensemble averaged velocity fields of 84 cycles, demonstrating the spray effect on air flow after injection.

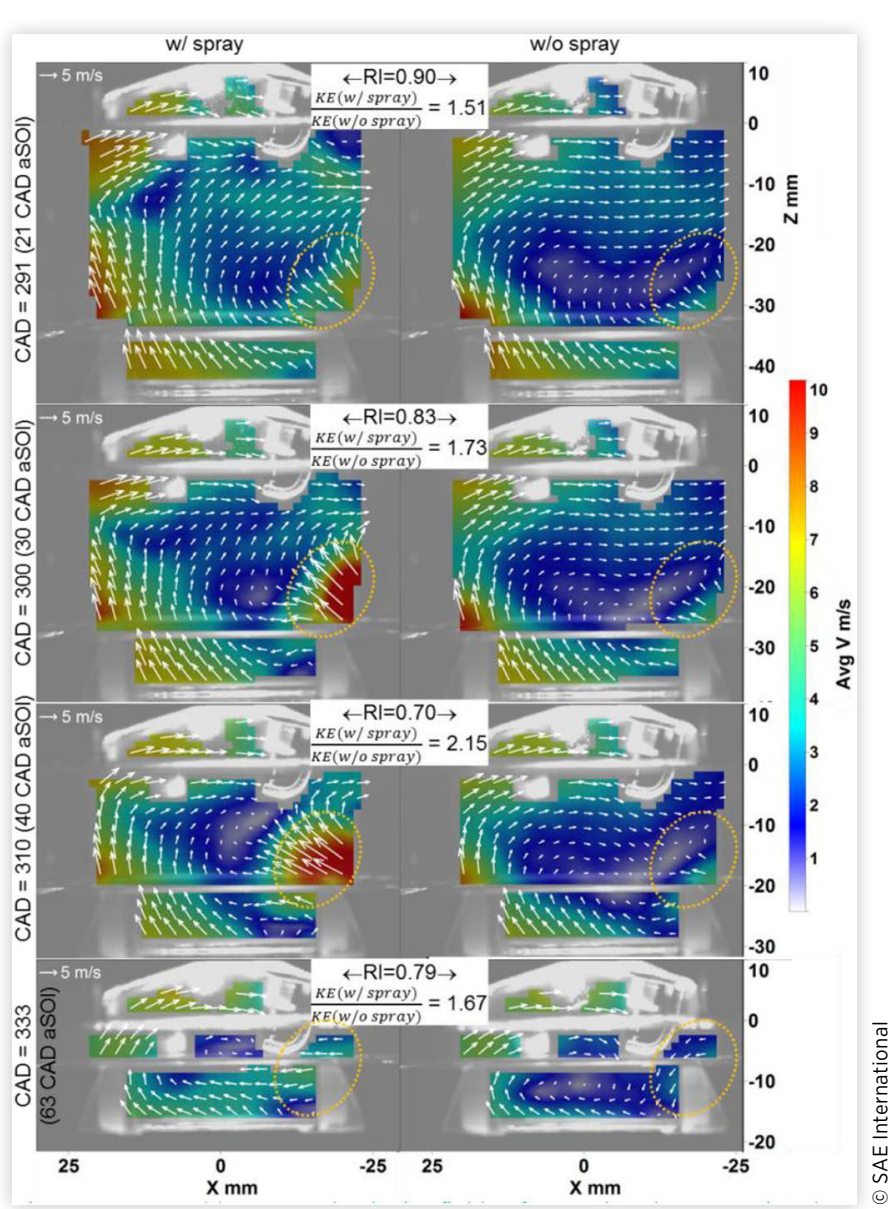

FIGURE 12 Ensemble averaged velocity field of fuel droplets at CAD $=285$ (15 CAD aSOI).

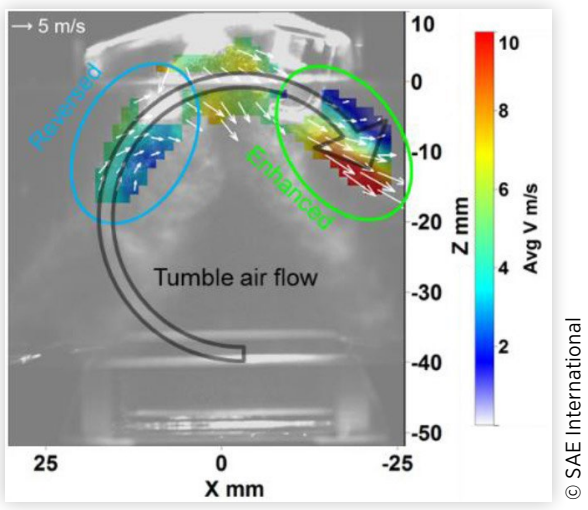

(c) 2018 SAE International. All Rights Reserved. 
fuel droplet velocity at the right side. It is assumed that the increased momentum on the right lead to the enhanced flow at the lower right (circle region). This effect lasted to the typical ignition timing, as shown in CAD $=333$ in Figure 11. In addition, the location of tumble center was changed at this CAD.

Figure 13 compares the flow structure between two set of flow data from SOI to typical ignition timing. Air flow of each none-fueled cycle was compared with all 84 fueled cycles using $R I$. Then the average and standard deviation of $R I$ is shown in Figure 13. CADs with spray present were not included in this comparison. This comparison of two sets of instantaneous velocity fields included both the spray impact on the air flow and the CCV of the flow. The same calculation was then applied to none-fueled conditions only to demonstrate the CCV. For the average $R I$, the $R I$ was similar before fuel injection, but after the fuel injection, the flow structure was changed by the spray, the average $R I$ reduced from 0.55 to 0.4 at $\mathrm{CAD}=310$. Then, the $R I$ increased which indicated the air flow structure was getting similar with none-fueled condition. The standard deviation of flow structure was not significantly affected.

Figure 14 depicts the same comparison used in Figure 13 but for kinetic energy ratio. It is obvious that the spray increased the kinetic energy and its variation. The kinetic energy of air flow was doubled between CAD $=304$ to

\section{FIGURE 13 Air flow structure comparison by computing} the $R /$ between instantaneous cycles, average and standard deviation were shown.

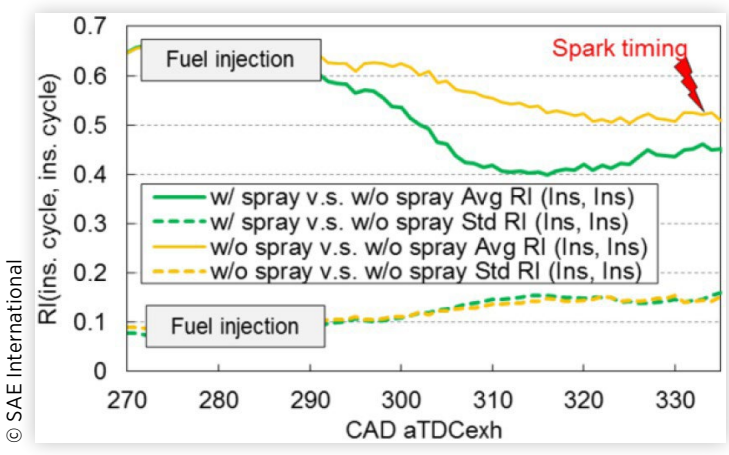

FIGURE 14 Comparison of kinetic energy of air flow by KER (w/spray divided by w/o spray), average and standard deviation were shown.

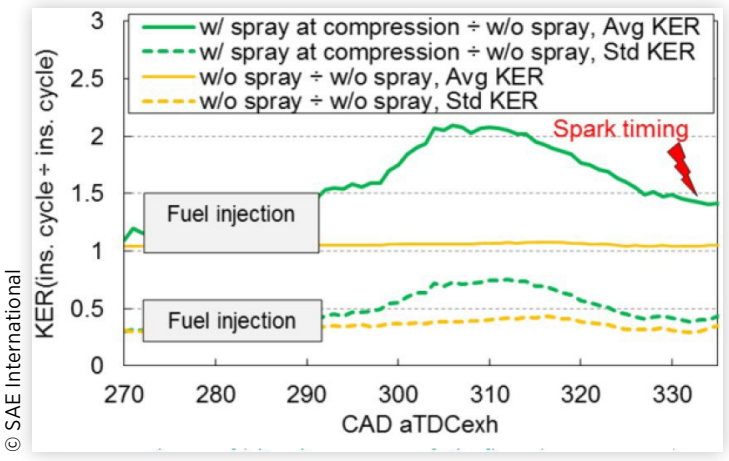

$\mathrm{CAD}=314$, and then the kinetic energy reduced. At typical ignition timing, the kinetic energy of the spray condition is still about $40 \%$ higher than for the none-fueled condition. In summary, due to the short time between injection and ignition timing, the spray influence lasted long enough to change the air flow structure and increase the kinetic energy at ignition timing.

\section{Homogeneous-Charge Mode}

The fuel spray injected during the intake stroke encounters lower temperature, lower density, and higher velocity air flow than during compression. Figure 15 shows the ensemble averaged velocity fields for without fuel and with fuel at SOI $=50$ aTDCexh, before and during the fuel injection. The velocity scale is different in Figure 15 due to the higher velocities of the intake jet. At CAD $=50$, the ensemble-averaged air flow with and without injection was nearly identical as quantified by the $R I$ and $K E R$. A strong air intake jet with a maximum speed of $40 \mathrm{~m} / \mathrm{s}$ was observed for both cases, none-fueled and fueled. As the spark plug blocked this strong intake jet, the air flow at the right side of spark plug was rather weak (0 17 m/s).

During fuel injection $(\mathrm{CAD}=55)$, the large-scale flow structure with and without injection was not significantly affected as reflected by an $R I$ of close to 1 . However, the KER between two average velocity fields quantified that the air flow was weakened by $15 \%$. Similar to the stratified-charge mode, locations near to the spray were affected. As highlighted by the dashed rectangle in Figure 15, the intake jet was affected. In addition, the air flow along the cylinder axis was weakened as the air entrainment (by the fuel injection) has opposite direction with the intake jet flow. This is quantified in Figure 16, in which the velocity component along the cylinder axis direction was reduced by $21 \%$ at the point closest to the spray. The u-velocity was also slightly affected on the spray side.

Figure 17 shows the ensemble averaged velocity fields at $\mathrm{CAD}=333$ (typical ignition timing) for homogenous-charge mode and none-fueled condition. Owing to the long delay

\section{FIGURE 15 Ensemble averaged velocity fields from} 84 cycles (every fourth vector shown).

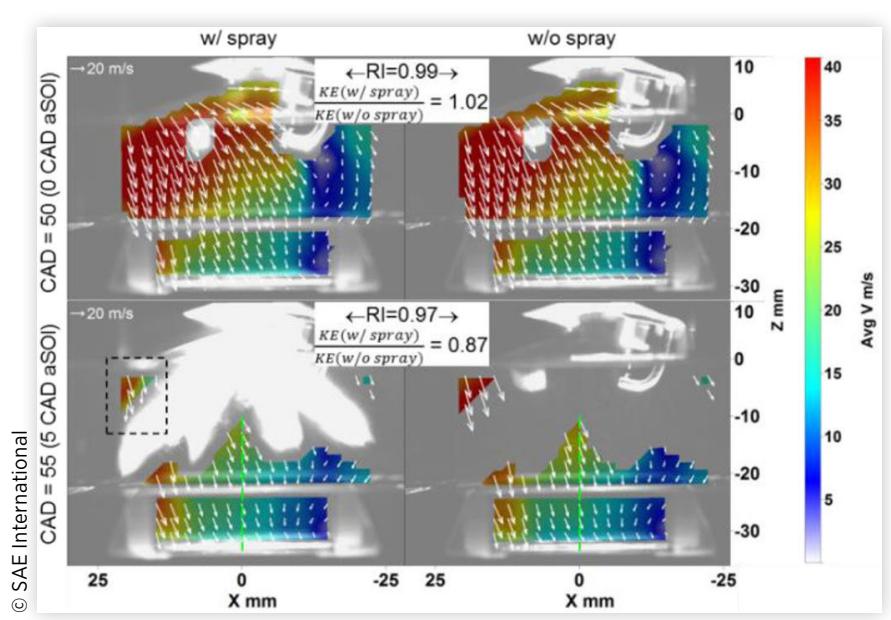


FIGURE 16 The velocity components comparison along the cylinder axis (average \pm standard deviation of 84 cycles were shown).

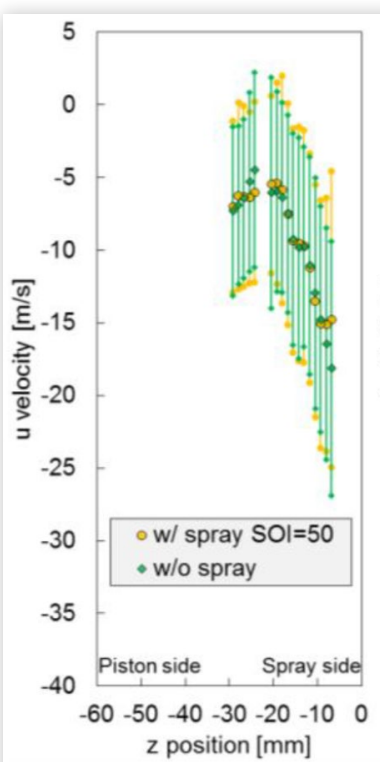

(a)

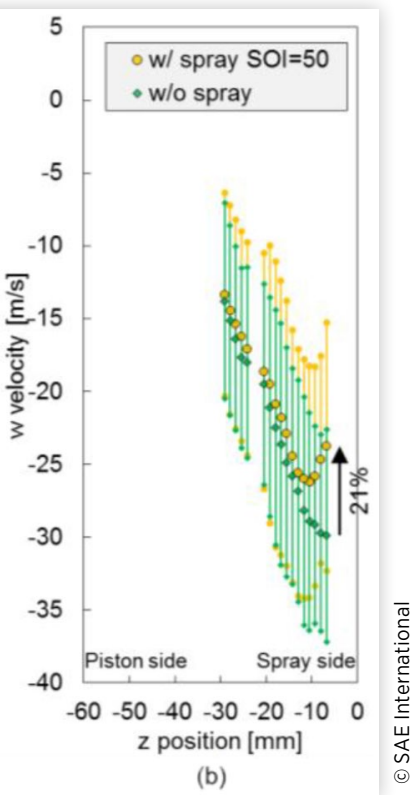

(b)
FIGURE 17 Ensemble averaged velocity fields from 84 cycles at $C A D=333$ (typical ignition timing).

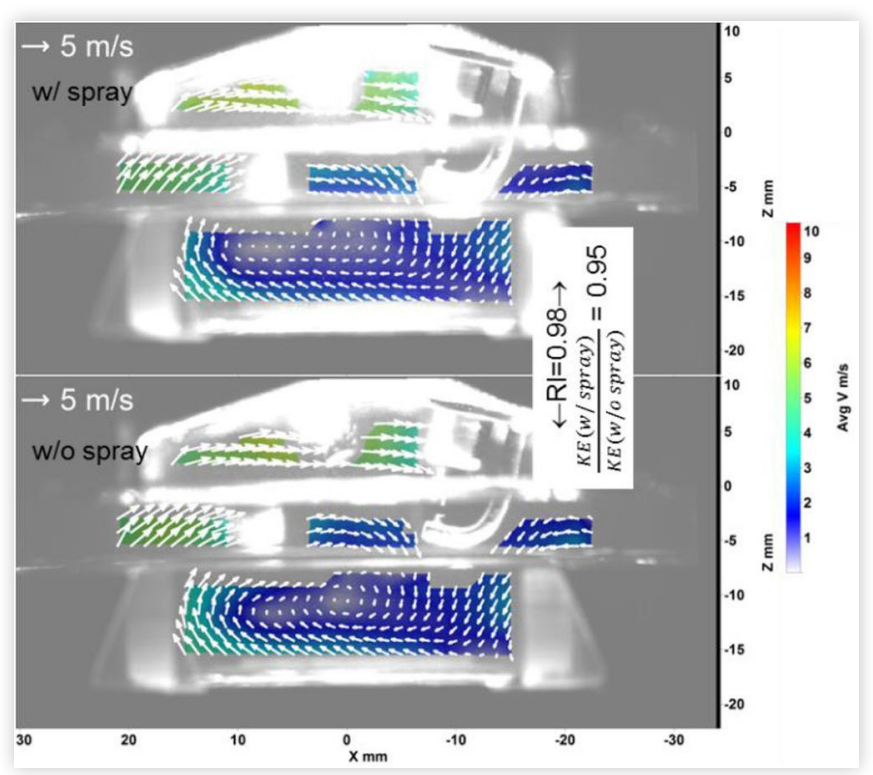

between fuel injection and ignition for homogenous-charge mode, the average air flow at $\mathrm{CAD}=333$ was nearly identical for fueled and none-fueled conditions. Figure 18 compares the flow structure between two sets of flow data at three CADs before injection, 16 CADs after injection, and typical ignition timing. The average and standard deviation of $R I$ is shown in the figure. The spray changed the flow structure right after the injection, but the flow structures are nearly identical at the typical ignition timing. The CCV of flow structure, represented by the standard deviation of $R I$, was nearly the same for all CADs shown in Figure 18.
FIGURE 18 Air flow structure comparison by computing the $R /$ between instantaneous cycles, average and standard deviation were shown.

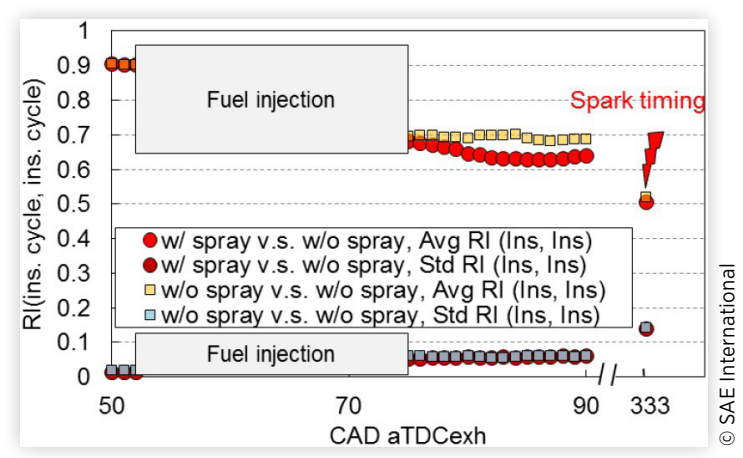

FIGURE 19 Comparison of kinetic energy of air flow by KER (w/spray divided by w/o spray), average and standard deviation were shown.

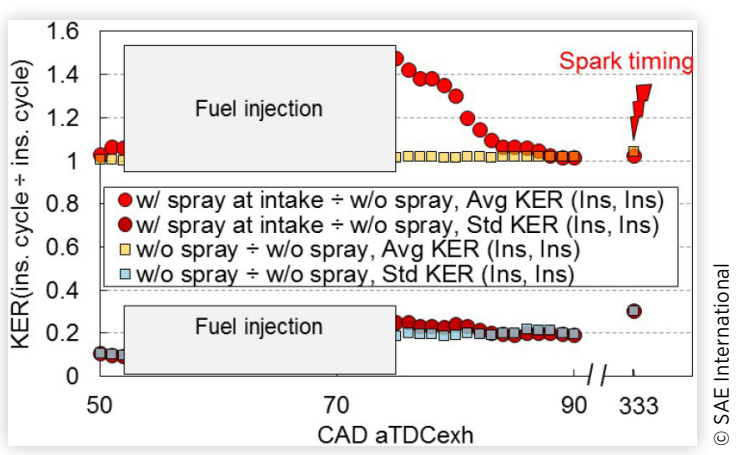

The kinetic energy comparison is shown in Figure 19. Even though the spray reduced the kinetic energy at $\mathrm{CAD}=55$ (Figure 15), the kinetic energy of air flow was raised after the injection. The reason being that the liquid spray moved in the same direction as the intake air jet, and therefore increased the total momentum of the intake jet. The maximum increase is approximately $50 \%$, but the kinetic energy was similar 34 CAD aSOI. The CCV of kinetic energy was slightly increased after injection, but it is nearly the same 34 CAD aSOI as well.

\section{Summary/Conclusions}

In this study, the air-fuel interactions in a SIDI optical engine were investigated. Crank-angle resolution PIV was conducted to measure the air flow and spray structure at the same time. Fuel injection during intake and compression strokes were compared with none-fueled condition to study the air-fuel interactions.

The major findings at the measured tumble plane for fuel injection during the compression stroke can be summarized as follows.

1. Based on the relevance index $(R I)$ and kinetic energy ratio $(K E R)$ correlations between $\mathrm{CAD}=275$ and $\mathrm{CAD}=270$, the overall air flow was not significantly affected by sprays during injection. 
2. Fuel injection led to air entrainment, which affected the air flow between fuel plumes. The air flow between two fuel plumes on the intake side was strengthened by approximately $2.4 \mathrm{~m} / \mathrm{s}$. The fuel spray speed was slightly correlated with this air flow enhancement.

3. Along the cylinder axis, the air entrainment resulted in an air flow towards the cylinder head, with maximum speed of $3.2 \pm 2.2 \mathrm{~m} / \mathrm{s}$ at the location closest to the spray.

4. $21 \mathrm{CADs}$ after SOI, fuel was fully atomized and the kinetic energy of the air flow was enhanced by $51 \%$. Between CAD $=304$ and 313, the kinetic energy of the air flow was doubled by the fuel injection.

5. As ignition timing was shortly after the injection, air flow structure was changed by the spray at typical ignition timing $(R I=0.79$ at $\mathrm{CAD}=333)$. At this $\mathrm{CAD}$, the kinetic energy was still $43 \%$ higher than for none-fueled operation.

6. The fuel injection did not affect the CCV of air flow structure, but increased the CCV of kinetic energy which might increase the combustion CCV.

The findings for fuel injection during the intake stroke can be summarized as follows.

1. Air entrainment induced by the spray affected the air flow in the same region as for stratified operation. The effect was different in details because of the different air flow conditions. Specifically, the air flow kinetic energy during the spray event was reduced by the injection because the original air flow direction was opposite to the air entrainment.

2. Spray changed the air flow structure shortly after the fuel injection, and increased the kinetic energy (maximum increase of $48 \%$ ) of the air flow.

3. Due to the long period from injection to ignition, the air flow structure and kinetic energy, as well as the CCV were similar for operations with and without fuel spray at typical ignition timing.

The major limitation of current study is that the measurement was done within one tumble plane. Different observations should be expected at other planes. As in-cylinder air-fuel mixing is a complex $3 \mathrm{D}$ process, $3 \mathrm{D}$ measurement $[\underline{20}$, 34] holds the great potential to provide deeper insight.

\section{References}

1. Zhao, F., Lai, M.-C., and Harrington, D.L., "Automotive Spark-Ignited Direct-Injection Gasoline Engines," Progress in Energy and Combustion Science 25(5):437-562, 1999.

2. Reuss, D.L., "Cyclic Variability of Large-Scale Turbulent Structures in Directed and Undirected IC Engine Flows," SAE Technical Paper 2000-01-0246, 2000, doi:https://doi. org/10.4271/2000-01-0246.

3. Funk, C.O., Sick, V., Reuss, D., and Dahm, W., "Turbulence Properties of High and Low Swirl In-Sylinder Flows," SAE Technical Paper 2002-01-2841, 2002, doi:https://doi. org/10.4271/2002-01-2841.
4. Chen, H., Xu, M., and Hung, D., "Analyzing In-cylinder Flow Evolution and Variations in a Spark-Ignition DirectInjection Engine Using Phase-Invariant Proper Orthogonal Decomposition Technique," SAE Technical Paper 2014-01-1174, 2014, doi:https://doi. org/10.4271/2014-01-1174.

5. Blessinger, M. et al., "Quantitative Mixing Measurements and Stochastic Variability of a Vaporizing Gasoline DirectInjection Spray," International Journal of Engine Research 16(2):238-252, 2014.

6. Chen, H. et al., "Analyzing the Cycle-to-Cycle Variations of Pulsing Spray Characteristics by Means of the Proper Orthogonal Decomposition," Atomization and Sprays, 2013.

7. Hung, D.L.S. et al., "Experimental Investigation of the Variations of Early Flame Development in a Spark-Ignition Direct-Injection Optical Engine," Journal of Engineering for Gas Turbines and Power 136(10):101503-101503, 2014.

8. Fansler, T.D. et al., "Combustion Instability in Spray-Guided Stratified-Charge Engines: A Review," International Journal of Engine Research260-305, 2015.

9. Sick, V., "High Speed Imaging in Fundamental and Applied Combustion Research," Proceedings of the Combustion Institute 34(2):3509-3530, 2013.

10. Harshavardhan, B. and Mallikarjuna, J.M., "Effect of Piston Shape on In-Cylinder Flows and Air-Fuel Interaction in a Direct Injection Spark Ignition Engine-A CFD Analysis," Energy 81(Supplement C):361-372, 2015.

11. Driscoll, K.D., Sick, V., and Gray, C., "Simultaneous Air/ Fuel-Phase PIV Measurements in a Dense Fuel Spray," Experiments in Fluids 35(1):112-115, 2003.

12. Ming, Z., Min, X., and David, L.S.H., "Simultaneous TwoPhase Flow Measurement of Spray Mixing Process by Means of High-Speed two-Color PIV," Measurement Science and Technology 25(9):095204, 2014.

13. Ghasemi, A. et al., "Multi-plume Sprays Interacting with Subsonic Compressible Gas Jets," Applied Energy 190(Supplement C):623-633, 2017.

14. Stiehl, R. et al., "Influence of Intake Geometry Variations on in-Cylinder Flow and Flow-Spray Interactions in a Stratified Direct-Injection Spark-Ignition Engine Captured by TimeResolved Particle Image Velocimetry," International Journal of Engine Research 17(9):983-997, 2016.

15. Stiehl, R. et al., "In-Cylinder Flow and Fuel Spray Interactions in a Stratified Spray-Guided Gasoline Engine Investigated by High-Speed Laser Imaging Techniques," Flow, Turbulence and Combustion 91(3):431-450, 2013.

16. Zeng, W., Sjöberg, M., and Reuss, D.L., "PIV Examination of Spray-Enhanced Swirl Flow for Combustion Stabilization in a Spray-Guided Stratified-Charge Direct-Injection SparkIgnition Engine," International Journal of Engine Research 16(3):306-322, 2015.

17. Zeng, W., Sjöberg, M., and Reuss, D.L., "Combined Effects of Flow/Spray Interactions and EGR on Combustion Variability for a Stratified DISI Engine," Proceedings of the Combustion Institute 35(3):2907-2914, 2015.

18. Zhang, X. et al., "The Interactions of in-Cylinder Flow and Fuel Spray in a Gasoline Direct Injection Engine with Variable Tumble," Journal of Engineering for Gas Turbines and Power 137(7):071507-1-071507-11, 2015. 
19. Chen, H. et al., "Proper Orthogonal Decomposition Analysis of Fuel Spray Structure Variation in a Spark-Ignition DirectInjection Optical Engine," Experiments in Fluids 55(4):112, 2014.

20. Chen, H., Lillo, P.M., and Sick, V., “Three-Dimensional Spray-Flow Interaction in a Spark-Ignition Direct-Injection Engine," International Journal of Engine Research 17(1):129138, 2016.

21. Disch, C. et al., "Investigations of Spray-Induced Vortex Structures during Multiple Injections of a DISI Engine in Stratified Operation Using High-Speed-PIV," SAE Technical Paper 2013-01-0563, 2013.

22. Aleiferis, P.G. and Behringer, M.K., "Modulation of Integral Length Scales of Turbulence in an Optical SI Engine by Direct Injection of Gasoline, Iso-Octane, Ethanol and Butanol Fuels," Fuel 189:238-259, 2017.

23. Abraham, P.S., Reuss, D.L., and Sick, V., "High-Speed Particle Image Velocimetry Study of In-Cylinder Flows with Improved Dynamic Range," SAE Paper 2013-01-0542, 2013, doi:https://doi.org/10.4271/2013-01-0542.

24. Zhuang, H., Sick, V., and Chen, H., "Impact of Fuel Sprays on in-Cylinder Flow Length Scales in a Spark-Ignition DirectInjection Engine," SAE International Journal of Engines 10(3), 2017.

25. Megerle, M., Sick, V., and Reuss, D.L., "Measurement of Digital PIV Precision Using Electrooptically-Created Particle-Image Displacements," Measurement Science and Technology 13:997-1005, 2002.

26. Reuss, D.L., Megerle, M., and Sick, V., "PIV Measurement Errors When Imaging through a Transparent Engine Cylinder," Measurement Science and Technology 13:10291035, 2002.

27. Liu, K. and Haworth, D., "Development and Assessment of POD for Analysis of Turbulent Flow in Piston Engines," SAE Technical Paper 2011-01-0830, 2011, doi:https://doi. org/10.4271/2011-01-0830.

28. Chen, H. et al., "A Practical Guide for Using Proper Orthogonal Decomposition in Engine Research," International Journal of Engine Research 14(4):307-319, 2013.

29. Chen, H., Reuss, D.L., and Sick, V., "On the Use and Interpretation of Proper Orthogonal Decomposition of in-
Cylinder Engine Flows," Measurement Science and Technology 23(8):085302, 2012.

30. Ishikawa, N. and Zhang, L., "Characteristics of Airentrainment in a Diesel Spray," SAE International 1999-010522, 1999, doi:https://doi.org/10.4271/1999-01-0522.

31. Nishida, K. et al., "Effects of Micro-Hole Nozzle and UltraHigh Injection Pressure on Air Entrainment, Liquid Penetration, Flame Lift-off and Soot Formation of Diesel Spray Flame," International Journal of Engine Research 18(1-2):51-65, 2017.

32. Peterson, B. and Sick, V., "Simultaneous Flow Field and Fuel Concentration Imaging at $4.8 \mathrm{kHz}$ in an Operating Engine," Applied Physics B 97(4):887-895, 2009.

33. Peterson, B., Reuss, D.L., and Sick, V., "High-Speed Imaging Analysis of Misfires in a Spray-Guided Direct Injection Engine," Proceedings of the Combustion Institute 33(2):30893096, 2011.

34. Chen, H. and Sick, V., "Three-Dimensional ThreeComponent Air Flow Visualization in a Steady-State Engine Flow Bench Using a Plenoptic Camera," SAE International Journal of Engines 10(2):625-635, 2017, doi:https://doi. org/10.4271/2017-01-0614.

\section{Contact Information}

\section{Dr. Hao Chen}

haochen@umich.edu

\section{Mr. Hanyang Zhuang} zhuanghany11@sjtu.edu.cn

Dr. David L. Reuss dreuss@umich.edu

Prof. Volker Sick

vsick@umich.edu

\section{Acknowledgments}

This work is supported by the Engine Systems Division of the General Motors - University of Michigan Automotive Collaborative Research Laboratory. 